\title{
Desenho gráfico de cartazes como instrumento social de empoderamento feminino
}

\author{
Graphic design of posters as social instrument for women's \\ empowerment
}

\author{
BERNARDI, Cristal \\ Universidade Federal de Santa Maria - UFSM I cristal.bernardi@gmail.com \\ BROD JÚNIOR, Marcos \\ Universidade Federal de Santa Maria - UFSM I brodjr74@gmail.com
}

\begin{abstract}
Resumo
Este artigo resulta de interação entre o Design Gráfico e o Empoderamento Feminino, interpretando a relação do desenho de Comunicação Visual com a mudança de comportamento, atitudes e valores humanos. Foi proposto que o Cartaz sirva como instrumento social, resultando em produto voltado ao coletivo, através de comunicação que promova a Igualdade de Gênero e favoreça a promoção da afirmação feminina. Como delimitação, pesquisou-se temas que relacionam as responsabilidades sociais do Desenhador e os projetos de Comunicação Visual do Movimento Feminista, evidenciando o Cartaz como mecanismo de mobilização das mulheres. Foi criado e aplicado um Questionário Virtual de Criação Coletiva, cujas respostas fundamentaram o desenho gráfico de duas coleções de cartazes sobre e para o tema, assim como a apreciação (validação) das soluções desenvolvidas. Acredita-se que o Cartaz foi mostrado como ferramenta voltada à transformação social ao promover a lgualdade de Gênero.
\end{abstract}

Palavras-chave: Desenho gráfico. Cartaz. Empoderamento feminino.

\section{Abstract}

This paper results from the interaction of Graphic Design and Women's Empowerment - that is, the relationship between visual communication and the change in behavior, attitude and human values. In this context, we believe that Posters can act as social instrument of change - products aimed to the collective, which promotes gender equality and favors women's empowerment through communication strategies. A literature review was conducted on the social responsibilities of the designer and on visual communication products of the Feminist Movement, especially Posters that help foster women's engagement. By this logic, a questionnaire on collective creation was designed and applied on-line. Data collected with the questionnaire supported the graphic design of two collections of posters about (and for) women's empowerment, as well as the assessment of the pieces. It is concluded that posters serve as tools for social transformation, with power to promote gender equality and favor Women's Empowerment.

Keywords: Graphic design. Posters. Women's empowerment. 


\section{INTRODUC̣ÃO}

Como apontado por Frascara (2004, 2006), os desenhadores desempenham papel fundamental na sociedade com relação ao crescente fluxo de informações visuais, tendo sobre ele responsabilidades não só profissionais como éticas, sociais e culturais. Frente ao argumento, este artigo apresenta - Design Gráfico com ênfase no Desenho de Comunicação Visual enquanto uma ferramenta de mobilização social em movimentos da sociedade civil, sem vínculos governamentais ou comerciais, ou seja, demonstra um exercício do Design Gráfico socialmente engajado, contestador, ativista, dedicado à propaganda de ideologias de responsabilidade social com uma visão construtiva do bem-estar coletivo e distante da área de interesse do consumo (NEVES, 2009). Assim, no presente artigo, discutir-se-á o cartaz como um dos modos de interação entre a Comunicação Visual e o Empoderamento Feminino.

Na sociedade contemporânea, aponta Neves (2009), o cartaz é reconhecido como um meio de expressão pessoal ou de grupos, sendo usado como suporte à difusão de ideologias e objetivos políticos e sociais. Para a autora, o cartaz assumiu, com mais força, um engajamento com as questões sociais, culturais e políticas na sociedade, sendo uma forma de protesto, cobrança política e incentivo para uma mudança de atitude em benefício da sociedade. Já nos anos 1960, os cartazes darão suporte para o movimento de libertação das mulheres, destaca Neves (2009, p. 73). De acordo com Silva e Camurça (2010), em sua forma moderna o feminismo constituiu-se como parte do campo político dos movimentos sociais de caráter democrático e popular, e luta até hoje por direitos e pelo reconhecimento das mulheres como sujeito político. De acordo com Sen (2000, apud MAGESTE; MELO; CKAGNAZAROFF, 2008), o feminismo evoluiu e enfatiza o papel da mulher atualmente também como agente ativo de transformação social.

Nessa perspectiva, espera-se legitimar a necessidade deste estudo ao propor que o Design Gráfico sirva como um importante meio voltado aos problemas sociais, apontando a utilização do cartaz como política sociocultural, visando a mobilização do gênero feminino para a luta feminista e beneficiando as mulheres como agentes de transformação social.

\section{OBJETIVOS}

O objetivo geral foi o de investigar a relação existente entre o Design Gráfico e o Empoderamento Feminino. Os objetivos específicos foram: (i) estudar a Comunicação Visual e sua relação com a mudança de comportamento, atitudes e valores humanos; (ii) pesquisar aspectos técnicos, estéticos e éticos da peça gráfica cartaz; e (iii) desenvolver como projeto uma série de cartazes 
sobre e para empoderamento feminino. Neste contexto, foi proposto se que o cartaz sirva como produto do desenho gráfico voltado aos problemas sociais, através da comunicação que promova a igualdade de gênero e favoreça o Empoderamento Feminino.

\section{FUNDAMENTAC̣̃̃O TEÓRICA}

Para fundamentar o projeto foram delimitados três pilares teóricos (Conceitos Básicos, Princípios Universais do Design; e a peça gráfica Cartaz) que sustentarão o eixo central desta investigação, ou seja, o desenho gráfico para mudança social e o empoderamento feminino. O primeiro conceito básico, refere-se ao Desenho Industrial onde, segundo Löbach (2000, p. 141), o trabalho do designer industrial consiste em encontrar uma solução para um problema, concretizada em um projeto de produto industrial, incorporando as características que possam satisfazer as necessidades humanas, de forma duradoura. De acordo com Redig (1983), o produto resultante do projeto de Desenho Industrial se endereça simultânea e inquestionavelmente, a todos aqueles que dele necessitam e para os quais o produto tem um determinado sentido, seja de caráter funcional, social ou cultural. A segunda conceituação básica é a compreensão sobre a relação entre o Design Gráfico e Desenho de Comunicação Visual. Com base em Coelho (2008), na área do Design, os conceitos de Design Gráfico, Comunicação Visual e Programação Visual praticamente se mesclam, ou melhor, podem ser apontados como sendo a mesma coisa. Segundo André Villas-Boas (2003), o Design Gráfico se refere à área de conhecimento e à prática profissional relativas ao arranjo estéticoformal de elementos textuais e não textuais que integram peças gráficas destinadas à reprodução com objetivo terminantemente comunicacional. De acordo com Frascara (2006), o Desenho de Comunicação Visual inclui os três elementos método (desenho), objetivo (comunicação) e meio (visão), exigidos para distinguir um campo de atividade. Conforme o autor, o desenhador de Comunicação Visual trabalha na análise, na composição e na apresentação visual de mensagens.

Quanto à terceira conceituação básica, sobre o Papel Social e Responsabilidades do Designer, Rodrigues (2009) aponta que é o de sair do compartimento no qual nasceu e foi socializado; é ir além das aparências culturais na busca do entendimento das essências primordiais da ordem social; é mergulhar no imaginário da sociedade e encontrar as conexões que unem (ou desunem) a teia das relações humanas; é identificar os símbolos culturais que tecem a imensa rede de comunicação; é desamarrar os nós encontrados no caminho, como fazem efetivamente os designers sociais. A utilização do Design Gráfico em movimentos de contestação social, acrescenta Neves (2009), tira o Design da atitude indiferente de um simples atendedor de demandas e o coloca como uma área de conhecimento influente e com um posicionamento 
próprio na sociedade, ou seja, uma área com voz influente. Com base em Frascara (2004), há quatro áreas de responsabilidade do designer: profissional (do desenhador frente ao cliente e ao público de criar uma mensagem que é detectável, discriminável, atraente e convincente); ética (criação de mensagens que apoiem os valores humanos básicos); social (produção de mensagens que façam uma contribuição positiva para a sociedade ou, ao menos, não importem uma contribuição negativa) e cultural (criação de objetos visuais que contribuem para o desenvolvimento cultural mais além dos objetivos operacionais do projeto).

Como quarto conceito inicial estão os Fatores Projetuais a serem considerados no projeto. No Desenho Industrial, de três de seus principais aspectos (função, mercadologia e fabricação) decorre um conjunto complexo de fatores projetuais que estão sempre competindo e, às vezes, estão em conflito direto, mas devem ser planejados até o produto final (MEDEIROS; GOMES, 2010, p. 113 apud SPERB et al., 2014). Medeiros e Gomes (2010, p. 120 apud SPERB et al., 2014) adaptaram e desdobraram os fatores de Redig (2005) e os de Archer (1966) resultando em: Filosofia (Estética / Ética), Geometria (Ordem / Arranjo), Psicologia (Percepção / Criação), Antropologia (Ideias / Comportamento), Ecologia (Conservação / Preservação), Economia (Custo / Valor), Ergonomia (Conforto / Adequação), Mercadologia (Preço / Promoção) e Tecnologia (Materiais / Fabricação). Esses fatores facilitam a compreensão das necessidades e prioridades do projeto, permitindo ao desenhador delimitar as ênfases projetuais para a solução do problema. Assim, para este trabalho, foram enfatizados os fatores Filosófico, Psicológico e Antropológico.

Quanto à quinta conceituação, sobre os tipos de projetos, Frascara (2006) diz que o campo do desenho de comunicação visual engloba quatro áreas ou tipos de projetos da prática profissional fundamentais: desenho para informação; persuasão; educação; e administração. O projeto tomou como argumento a obra de Abraham Antoine Moles (1969), que descreve o princípio da teoria geral da comunicação por cartazes, onde se visa primeiro informar, em seguida, motivar, isto é, efetuar uma operação similar à da educação; que persegue os objetivos, entre outros, de imprimir no cérebro dos seres humanos reflexos condicionados. No presente caso, tomou-se como base os estudos de desenho para Educação e Persuasão, que apontou a peça gráfica Cartaz como o produto a ser planificado. Para o produto a ser projetado foram escolhidos nove dos Princípios Universais do Design, de acordo com a classificação de Lidwell, Holden e Butler (2010), entre aqueles que melhor contribuem para o aprendizado das pessoas, sendo eles: Efeito de Mera Exposição, Pirâmide Invertida, Legibilidade, Mnemônica, Efeito da Superioridade da Imagem, Facilidade de Leitura, Relação Sinal/Ruído, Fator de Fixação e o Efeito von Restorff.

Ao indicar o cartaz como suporte da comunicação, Szaniecki (2007 apud NEVES, 2009) refere que o cartaz - ou pôster, pode ser caracterizado como 
um conjunto de imagens e de palavras, que visa transmitir uma mensagem prédeterminada em um único espaço plano, de maneira rápida e resumida, isto é, uma imagem fixa apoiada em um suporte e direcionada ao público. Conforme o autor, em relação ao seu impacto visual, podemos comparar o que o cartaz fez nas ruas com o que os filmes fizeram nas telas de cinema. Para Moles (1969), o cartaz é veiculado em vias públicas, é de fácil visualização por um número maior de pessoas e da forma mais instantânea possível. Moles (1969, p. 21) destaca que, geralmente, se utilizam as mesmas técnicas: "colar sobre um muro visto por todo o mundo uma folha de papel impressa, trazendo imagens ou signos acompanhados de um texto". O cartaz se tornou, portanto, instrumento de mecanismo social, sendo um modo de comunicação de massa criado para amparar um sistema institucional qualquer. De acordo com Neves (2009), o desenvolvimento da linguagem gráfica do cartaz andou junto com as mudanças e os aperfeiçoamentos dos movimentos artísticos e dos meios de comunicação, sendo um resultado da produção cultural e do desenvolvimento tecnológico da sociedade. Hollis (2000) conta que o cartaz moderno surgiu no século 19, a partir da união da arte com as recentes técnicas de reprodução daquela época: a litografia e, posteriormente, a cromolitografia. No final do século 19, os cartazes tomavam as ruas, se tornando a representação da sociedade e da cultura do seu público-alvo, especialmente nos assuntos relacionados ao comércio e ao entretenimento. Durante a Primeira Guerra, o cartaz político cresceu e ganhou força tornando um meio representativo de propaganda ideológica e de persuasão. Hollis (2000) descreve que, no interior das casas, os cartazes políticos e culturais converteram-se de objetos decorativos a símbolos de status e idealismo político de seu proprietário. Esses pôsteres foram além dos limites do Design Gráfico, já que não estavam mais associados apenas a interesses comerciais.

Quanto ao contexto urbano, de acordo com Gonzales (2013), atualmente, denomina-se mídia exterior o conjunto de meios que veiculam peças publicitárias como fachada, totem, front-light, backlight, painel digital, triedro, cartazes de rua, topo, relógio/termômetro, letreiro luminoso, placa de esquina, painel rodoviário e outdoor, entre outros. Entre eles está o cartaz de rua, também conhecido como lambe-lambe ou cartazetes, muitas vezes colocados em segunda opção, mas também muito atrativo ao público. Sua expansão superou as das mídias tradicionais como TV, rádio, revistas e jornais, por esse motivo ganha cada vez mais utilização nas estratégias de produtos, marcas e serviços. Pode-se afirmar assim, que uma das funções importantes do contexto urbano, é relatar sua história a partir da arquitetura, das praças e parques, monumentos, comércios, indústrias, população, geografia e meios de comunicação.

Silva (2015) diz que os lambe-lambes tem efeitos de sentido que são, na maioria das vezes, contraposições ao discurso dominante. 
[...] os cartazes lambe-lambe são modalidades de mídia que, de alguma forma, fogem do discurso globalizado e globalizante do consumo, originam-se, em grande parte, de rumores das periferias sociais e culturais. Funcionam como uma 'contra voz do discurso emitido pela mídia de massa ou que não encontram nela eco ou expressão', dessa forma, 'se apropriam ilegalmente dos espaços disponíveis na cidade para ganhar notoriedade' (SODRÉ, 2006 apud SILVA, 2015, p. 74-75).

Para Silva (2015), lambe-lambes constituem um impactante canal, por onde se expressam as opiniões individuais ou coletivas que não representam o discurso dominante da sociedade.

Depois de referenciar todos esses conceitos, foi posto em foco o eixo central do trabalho, ou seja, o assunto que une os três pilares da pesquisa e que engloba informações pertinentes para se alcançar o objetivo geral. No caso, o eixo central do trabalho evidencia a interação entre Empoderamento e a Comunicação Visual no feminismo.

Como conceito, "o feminismo é um movimento que confronta o sistema de dominação e propõe a transformação social, pois quer transformar a vida das mulheres e toda a sociedade" (SILVA; CAMURÇA, 2010, p. 12). Para as autoras, o feminismo é simultaneamente uma teoria que analisa criticamente o mundo e a situação das mulheres, e um movimento social que luta por transformação e uma atitude pessoal diante da vida (SILVA; CAMURÇA, 2010). Assim, elas deixam de ser apenas receptoras passivas de auxílio para favorecer seu bem-estar e sua visualização como agentes ativos de transformação social que podem mudar a vida de mulheres e homens (SEN, 2000 apud MAGESTE; MELO; CKAGNAZAROFF, 2008).

Nos anos 1970, a expressão empoderamento iniciou a ser utilizada pelo Movimento Feminista, percebido como "a alteração dos processos e estruturas que reduzem as mulheres à posição de subordinada aos homens" (2002 apud MAGESTE; MELO; CKAGNAZAROFF, 2008, p. 1). Como desdobramento, entender "os avanços e retrocessos vivenciados pelas mulheres na sociedade é importante para a proposta de construção de uma sociedade mais igualitária, constituída de seres humanos individualizados e autônomos" (BAHIA; FERRAZ, 1999 apud MAGESTE; MELO; CKAGNAZAROFF, 2008, p. 11).

Conforme Martins (2003, apud MAGESTE; MELO; CKAGNAZAROFF, 2008 , p. 1) pelo seu prefixo, empoderar que dizer ação, sendo que, no sentido atual, o "empoderamento quer dizer a transformação de um sujeito em agente ativo, por meio de processos que variam de acordo com a situação e o contexto". Segundo Gita Sen (1994 apud MONTEIRO, 2008), o empoderamento é delimitado como uma mudança nas relações de poder. Paulo Freire afirma que: 
[...] o empoderamento, como processo e resultado, pode ser concebido como emergindo de um processo de ação social no qual os indivíduos tomam posse de suas próprias vidas pela interação com outros indivíduos, gerando pensamento crítico em relação à realidade, favorecendo a construção da capacidade pessoal e social e possibilitando a transformação de relações sociais de poder. [...]. Uma educação para a emancipação, concebida como ação cultural para a libertação, pode se constituir em instrumento valioso em projetos e ações direcionados ao empoderamento dos sujeitos (FREIRE, 1979 apud BAQUERO, 2012, p. 34).

Sobre tipos de poder e níveis de empoderamento, Friedmann (1996 apud MONTEIRO, 2008) relaciona o empoderamento com o acesso e controle de três tipos de poderes: social, político e psicológico. Mageste, Melo e Ckagnazaroff (2008) propõem refletir o processo do empoderamento em três níveis: o individual, o relacional, e o contextual. Para Martins (2003 apud MAGESTE; MELO; CKAGNAZAROFF, 2008) no nível de análise individual o ponto de partida é a tomada de consciência pela mulher de que lhe falta instrumentos para expandir seu potencial por completo e o desejo de mudança. Mageste, Melo e Ckagnazaroff (2008) ressaltam que é importante se destacar no nível relacional a participação em grupos sociais que apoiam e incentivam o potencial feminino. Conforme os autores (2008), no nível contextual estão inseridas as questões de alcance de bem-estar, segurança econômica, reconhecimento social, individual e coletivo. Mundialmente, as mulheres sofrem riscos à vida, à saúde e ao seu bem-estar em função de sua sobrecarga de trabalho e pelo poder e influência insuficientes. Nesta fundamentação teórica também se somam elementos sobre os movimentos e iniciativas da Comunicação Visual no feminismo. Segundo Kirkham (2001, p. 342-373, tradução nossa).

[...] o sufrágio foi a questão central para o feminismo no início do século XX. [...] o cartaz de desenho simétrico de 1913 por Bertha M. Boyé, “Votes for Women”, reforça o senso de estabilidade serena que emana da estátua como figura em seu centro; o orbe que se levanta atrás de sua cabeça é um sol e uma auréola, sugere ambiguamente, calidez e virtude. O slogan do cartaz não aparece como um argumento ou um grito de batalha, mas como uma verdade inatacável, um "direito inalienável" cujo tempo tinha chegado. 
Figura 1 - Cartaz de Bertha Boyé, “Votes for Women”, 1913.

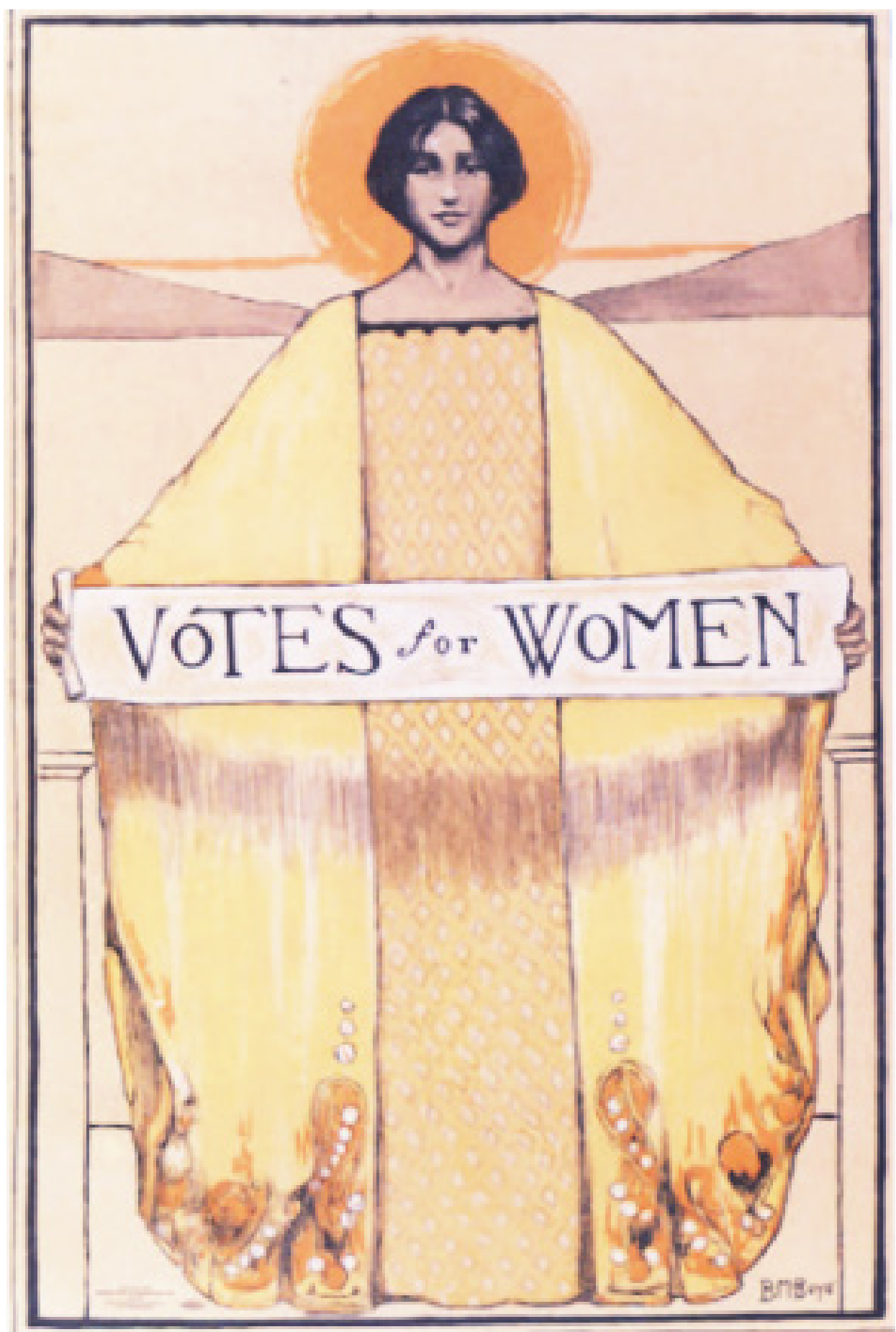

Fonte: Pat Kirkham (2001, p. 372).

Modernamente, destacam-se os grupos gráficos internacionais Chicago Women's Graphics Collective (1970 - 1983), See Red Women's Workshop (1974 - 1990), Guerrilla Girls (1985 - atualmente) e Barbara Kruger (1989 - atualmente). No âmbito nacional, destacam-se as atuações do Coletivo Amélia, Feminicidade, Lambe-buceta, Frida Feminista, Onde Jazz Meu Coração, Encontrarte, Manifesto das Mina, Empodere Duas Mulheres, Campanha Chega de Fiu-Fiu, Movimento Vamos Juntas?, Denisenhando e Carol Rossetti, dentre muitos outros. 


\section{O PROJETO E O PROCESSO CRIATIVO}

Depois da sua fundamentação teórica, o projeto do produto segue agora para sua etapa prática. O projeto utilizou o Método Especialista de Projeto de Produto de Serviço (BROD JUNIOR, 2004, 2009). A macroestrutura deste método baseou-se no Planejamento de Produto Industrial (PPI), proposto por Medeiros e Gomes (2003); a microestrutura foi estabelecida pelo Processo Criativo (GOMES, 2011): Identificação, Preparação, Incubação, Esquentação, Iluminação, Elaboração e Verificação.

\subsection{Identificação}

A etapa da Identificação serviu para a definição do produto, textualizando-o com base nos fatores projetuais. Nesta etapa, entendeu-se o processo de funcionamento e atuação de três campanhas da ONU (Eles por Elas; Una-se pelo Fim à Violência contra as Mulheres; e Livres \& Iguais), através da Lista de Verificação, definindo os atores principais (Desenhador, Usuário e Fabricador) por meio da Leitura de Fatores, equacionando-se com os nove fatores projetuais. A partir disto, mostrou que os serviços apresentados apoiam os valores humanos básicos e compreendem os aspectos de responsabilidades de todo o projeto. Estes se utilizam de mídias externas em conjunto com a internet e mídias sociais, como meio para ampliar a distribuição destas comunicações. Desta forma, os cartazes deste projeto também utilizarão a internet como apoio para distribuição de sua comunicação.

\subsection{Preparação}

Para Brod Junior (2004), a etapa de Preparação permite a construção e a organização de conhecimentos, através das Técnicas Analíticas Linguísticas e Desenhísticas, que são adequadas para a ampliação do vocabulário e da fluência projetual dos desenhadores. Nesta fase foram utilizadas técnicas analíticas para ampliar o vocabulário verbal e visual. Após todas as análises, observaram-se os elementos e as formas como os projetos com o mesmo objetivo, são feitos e apresentados. Verificou-se que os conteúdos auxiliam no processo de empoderamento feminino, porém, nem todos possuem um projeto gráfico. Portanto, pretende-se gerar alternativas propondo uma forma mais adequada e atraente para a transmissão das mensagens, procurando explorar recursos, temas e elementos pertinentes para o empoderamento feminino. 


\subsection{Incubação}

Após a fase de análise veio a fase de incubação, em que as informações obtidas durante as análises são armazenadas no inconsciente para, então, começar a fase de geração de alternativas do projeto. Para esse fim, com base nas pesquisas e análises feitas até este ponto, constatou-se a necessidade de encontrar e coletar informações pertinentes para os cartazes para Empoderamento Feminino. Portanto, foi planejado um Questionário Virtual de Criação Coletiva para cumprir este papel, o qual será apresentado na primeira fase do Processo Criativo a seguir, relacionado aos resultados da configuração final do projeto: Esquentação, lluminação, Elaboração e Verificação.

\subsection{Esquentação}

Para dar início ao processo de criação, criou-se um Questionário Virtual de Criação Coletiva, utilizando-se da ferramenta virtual Typeform.com, com o propósito de reunir opiniões e informações em conjunto para ajudar na escolha dos argumentos, temas, elementos e, ainda, recolher sugestões para o título (nome) do projeto de cartazes sobre Empoderamento Feminino. O conteúdo para as perguntas foi coletado no decorrer deste estudo. O Questionário correspondeu aos parâmetros da pesquisa qualitativa, quantitativa, aplicada, descritiva e experimental, utilizando-se do Método Dialético, aplicado no universo das mulheres, com amostra acidental entre 15 e 70 anos, onde se consideraram os conceitos de pesquisa segundo Antônio Carlos Gil (1994). Disponibilizado para preenchimento na Internet e divulgado nas redes sociais Facebook e Instagram, o Questionário Virtual de Criação Coletiva também foi enviado para contatos via e-mail. Sua composição redacional incluiu perguntas abertas (qual é a sua opinião?), fechadas (duas escolhas: sim ou não), de múltiplas escolhas (fechadas com uma série de respostas possíveis), uma questão para compartilhamento de conteúdo sobre Empoderamento Feminino, uma para a criação de hashtags e outra para sugerir o nome do projeto. O conteúdo foi dividido em três blocos temáticos: 1. Dados sociais e culturais; 2. Conteúdo gráfico-verbal; 3. Conteúdo gráfico-visual. Os participantes não eram obrigados a responder a todas as questões apresentadas. O Questionário Virtual de Criação Coletiva recebeu um total de 407 visitas e obteve um total de 19\% de participações, ou seja, 77 respostas, em um período de 15 dias (05/05 a 20/05/2017), com uma média de 5,13 respostas diárias, levando em média $18 \mathrm{~m} 19$ seg para seu preenchimento individual.

Concluído o Questionário de Criação Coletiva e feita a tabulação das respostas obtidas, iniciou-se a Lista de Requisitos (lógico informacionais, técnico funcionais, e estéticos formais) aos quais o projeto deve atender. Posteriormente, iniciou-se o estudo de alternativas para os cartazes e para o 
nome do projeto, baseadas nas respostas obtidas no Questionário de Criação Coletiva e na Lista de Requisitos. Dentre as técnicas utilizadas nesta etapa destacaram-se o briefing e brainstorming, processos que foram relacionados às essências do desenho (malhas gráficas, ilustração, tipografia e cores) com o desenho de Comunicação Visual e com os Princípios Universais do Design.

\section{5 lluminação}

Após o estudo de alternativas, iniciou-se a fase de produção visual da identidade das coleções de cartazes. Para a assinatura visual (nome), foi estudada a lista de sugestões obtida na pesquisa de campo, onde se constataram diferentes criações, pontos de vista e pensamentos correspondentes aos temas da investigação. A opção mais abrangente foi buscar um acrônimo, flexionando as palavras mais citadas nas respostas (mulher e empoderamento). Da criatividade, resultou a opção pelas respectivas versões em francês femme e em inglês empowerment, para favorecer a instantaneidade cultural, tendo em conta a universalização dos temas. Delas, foram extraídos o prefixo "fem" e o sufixo "power" que, conjugados, originam o título final: FemPower (Figura 2). O título mantém correspondência também com a expressão "Girl Power"1, utilizada na Internet; ainda está relacionado ao princípio da Mnemônica, conforme Lidwell, Holden e Butler (2010). FemPower significaria, assim, cartazes sobre o empoderamento e a defesa da condição feminina, de qualquer pessoa que possa se julgar mulher.

Figura 2 - Assinatura Visual FemPower.

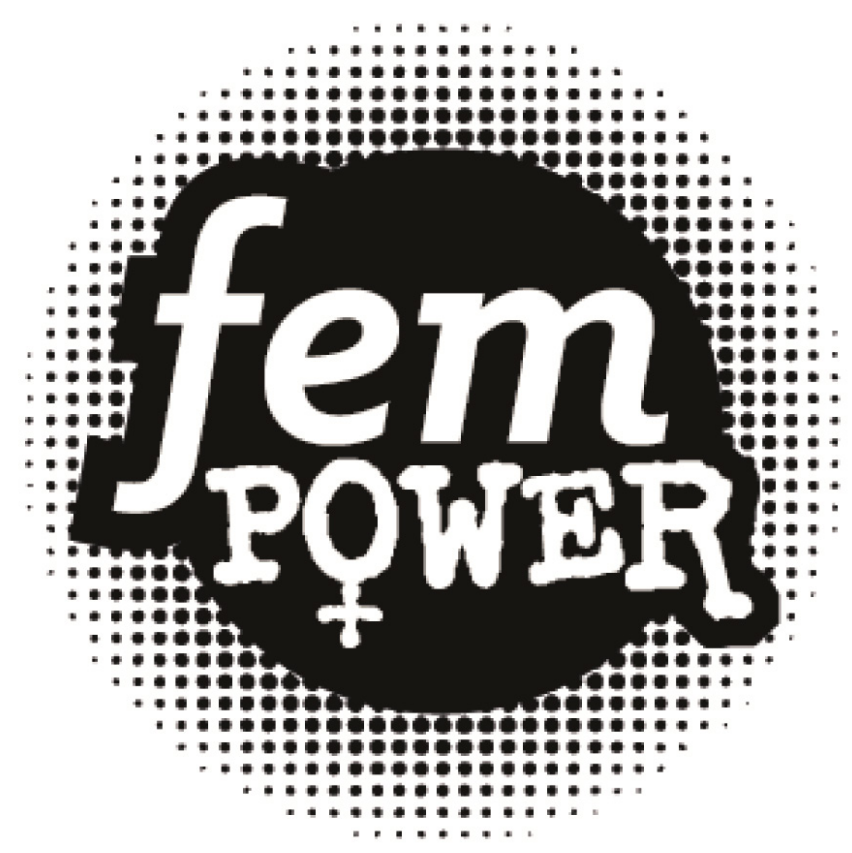

Fonte: Elaborado pelos autores (2017).

1 Segundo o site Wikipedia (2016), Girl Power é um termo para poder feminino, independência e autossuficiência. Expressa um fenômeno cultural da década de 1990 e do início dos anos 2000, estando também ligada à Terceira Onda do Feminismo. 
Para o conceito visual, o padrão de pontos foi adotado na totalidade do projeto, equivalendo subjetivamente às mulheres em todo o planeta que lutam por igualdade. Já as cores preta e branca foram escolhidas pelo alto contraste nas composições, além de ser a forma mais econômica para impressão em papel, possibilitando a reprodução por fotocopiadoras, sem perder a qualidade de informações. Também remete à expressão "preto no branco", isto é, "deixar claro". Já para a tipografia, a escolha foi baseada no conceito de diversidade de formas, buscando chamar e prender a atenção dos espectadores. Em relação aos cartazes, duas coleções, em tamanho A3 e A4, foram criadas:

(I) Coleção Empoderamento:

1. Violência Contra a Mulher: Esta série (Figura 3) utiliza dados da ONU Mulheres e da Lei Maria da Penha (Lei no 11340, de 07/08/2006), do Brasil. O enfoque é a realidade da violência de gênero no Brasil, os tipos de violência e como reconhecer situações.

Figura 3 - Série Violência Contra a Mulher.
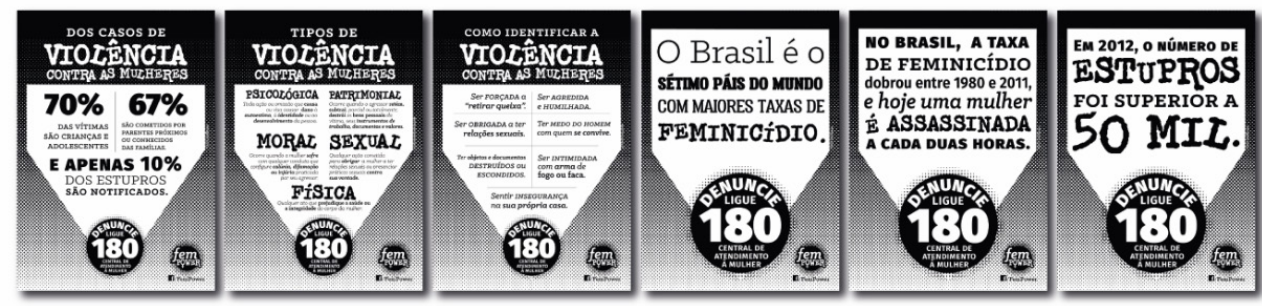

Fonte: Elaborado pelos autores (2017).

2. Desigualdade de Gênero e Raça: Os textos (Figura 4) são baseados nas publicações e dados oficiais distribuídos pela ONU Mulheres.

Figura 4 - Série Desigualdade de Gênero e Raça.

\begin{tabular}{|c|c|c|}
\hline $\begin{array}{l}\text { DeSticua é } \\
\text { de GẾNERO o RAcA! }\end{array}$ & $\begin{array}{l}\text { Desso é } \\
\text { deGÉTERTL L RAGA! }\end{array}$ & 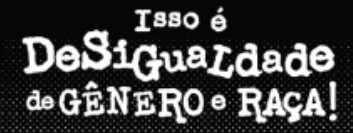 \\
\hline $\begin{array}{l}\text { AS MULHERES DEDICAM } \\
\text { MAIS DO QUE O DOBRO } \\
\text { DO SEU TEMPO PARA AS } \\
\text { DOMESTICAS } \\
\text { DO QUE OS HOMENS. }\end{array}$ & $\begin{array}{l}\text { Mulheres Negras } \\
\text { Elas recebem em média } \\
\mathbf{5 8 , 2} \% \text { da renda } \\
\text { das mulheres brancas, } \\
\text { cHEFIAM } 41,1 \% \text { das famílias } \\
\text { esão } 55,6 \text { MILHÕEs no Brasil. }\end{array}$ & $\begin{array}{l}\text { O \$ALÁRIO } \\
\text { MÉDIO PAGO AOS } \\
\text { HOMENS E } \\
30 \% \text { MAIOR } \\
\text { daquele pago às mulheres. }\end{array}$ \\
\hline & fem & fem \\
\hline
\end{tabular}

Fonte: Elaborado pelos autores (2017).

3. Direitos da Mulher: Esta série (Figura 5) mostra cada um dos Doze Direitos da Mulher, conforme a ONU. 
Figura 5 - Série Direitos da Mulher.
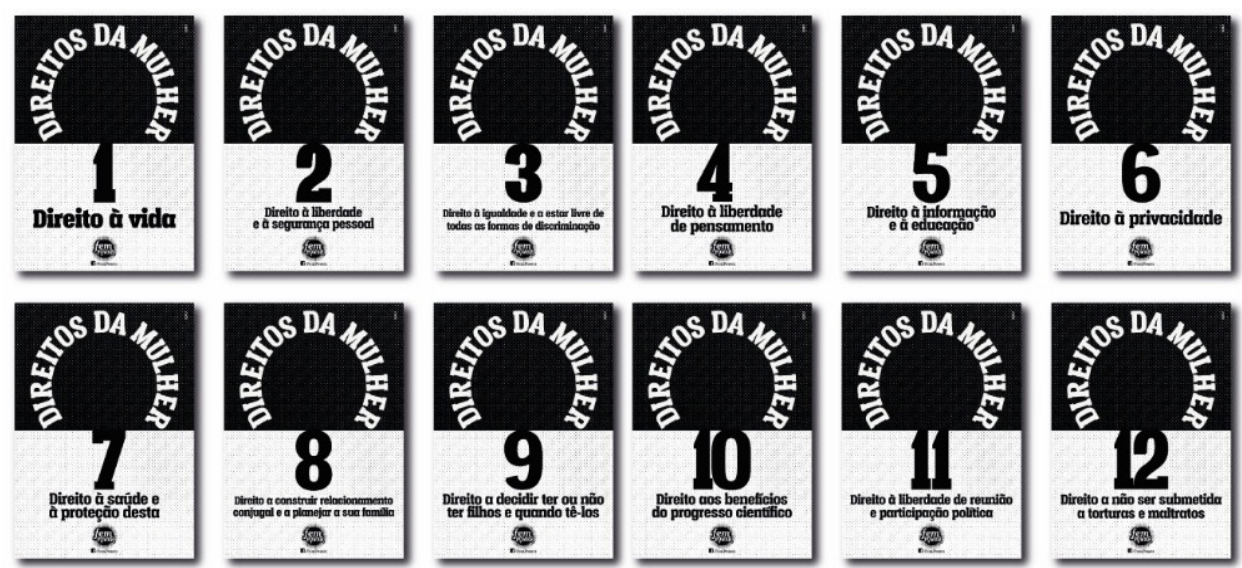

Fonte: Elaborado pelos autores (2017).

4. ODS-5: Esta série (Figura 6) ocupa-se das nove metas do Objetivo de Desenvolvimento Sustentável № 5 (ODS-5), da ONU, para o alcance da igualdade de gênero e empoderamento das mulheres.

Figura 6 - Série ODS 5.

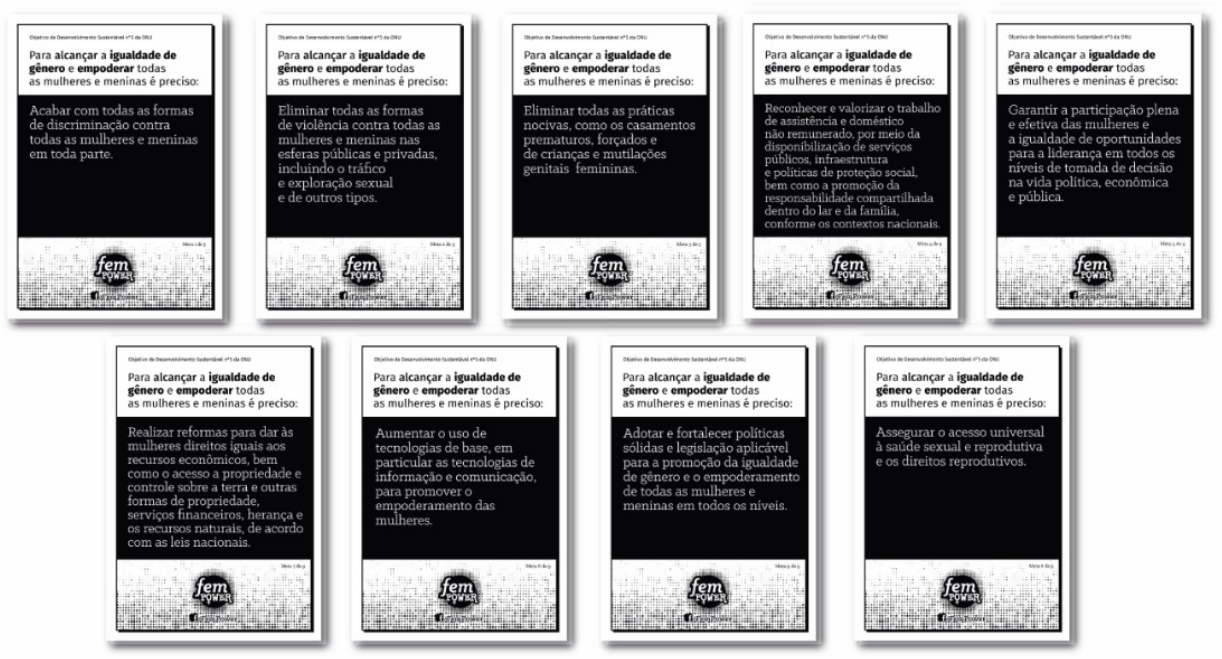

Fonte: Elaborado pelos autores (2017).

(II) Coleção FemPower

5. Perfis: As mulheres retratadas nesta série (Figura 7) foram sugeridas pelos participantes do Questionário Virtual de Criação Coletiva, apontadas como personalidades inspiradoras. 
Figura 7 - Série Perfis.
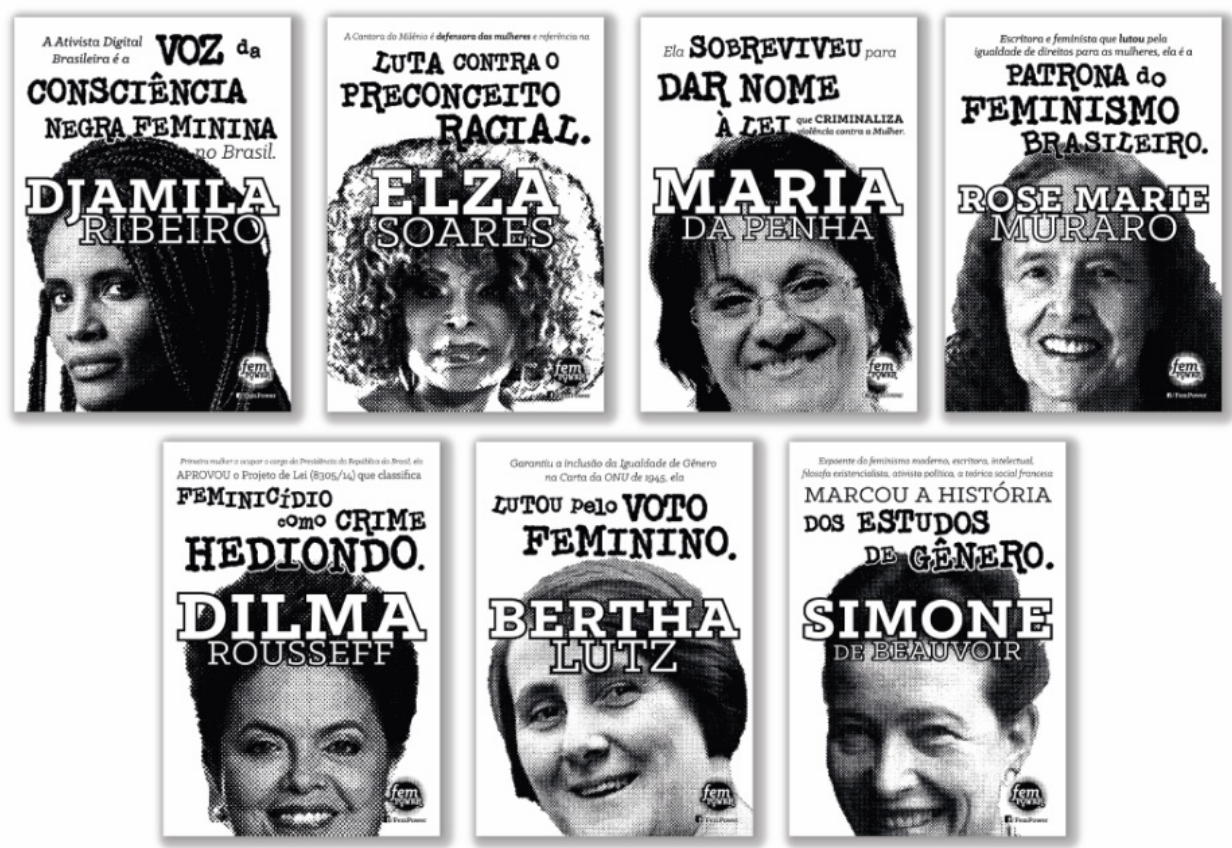

Fonte: Elaborado pelos autores (2017).

6. Feminismo, Una-se à Luta!: Nestes cartazes (Figura 8) foram usados textos do livro Feminismo e Movimento de Mulheres, de Carmen Silva e Silvia Camurça (2010), do Instituto Feminista para a Democracia - SOS Corpo.

Figura 8 - Série Feminismo, Una-se à Luta!

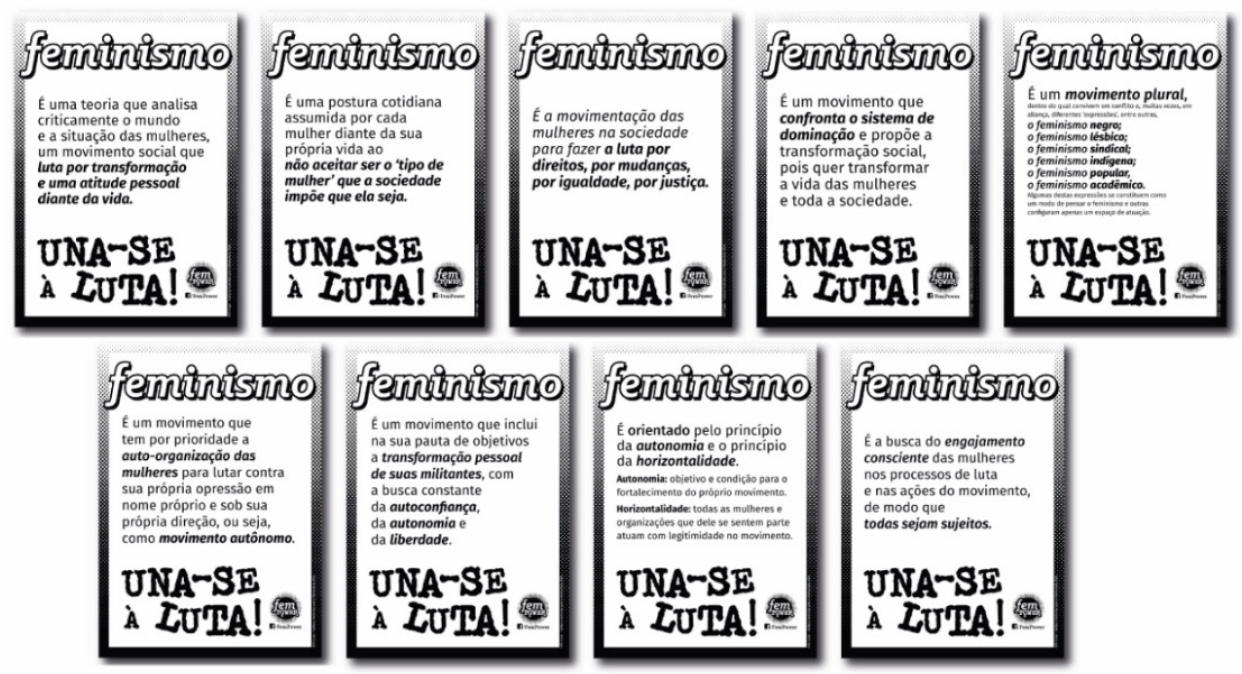

Fonte: Elaborado pelos autores (2017).

7. Mural Livre: A ideia central nesta série (Figura 9) é exatamente a do Mural Livre, sem julgamentos de coisas escritas em muros, em pichações, em músicas, em algum pedaço de papel preso no mural do corredor. 
Figura 9 - Série Mural Livre.

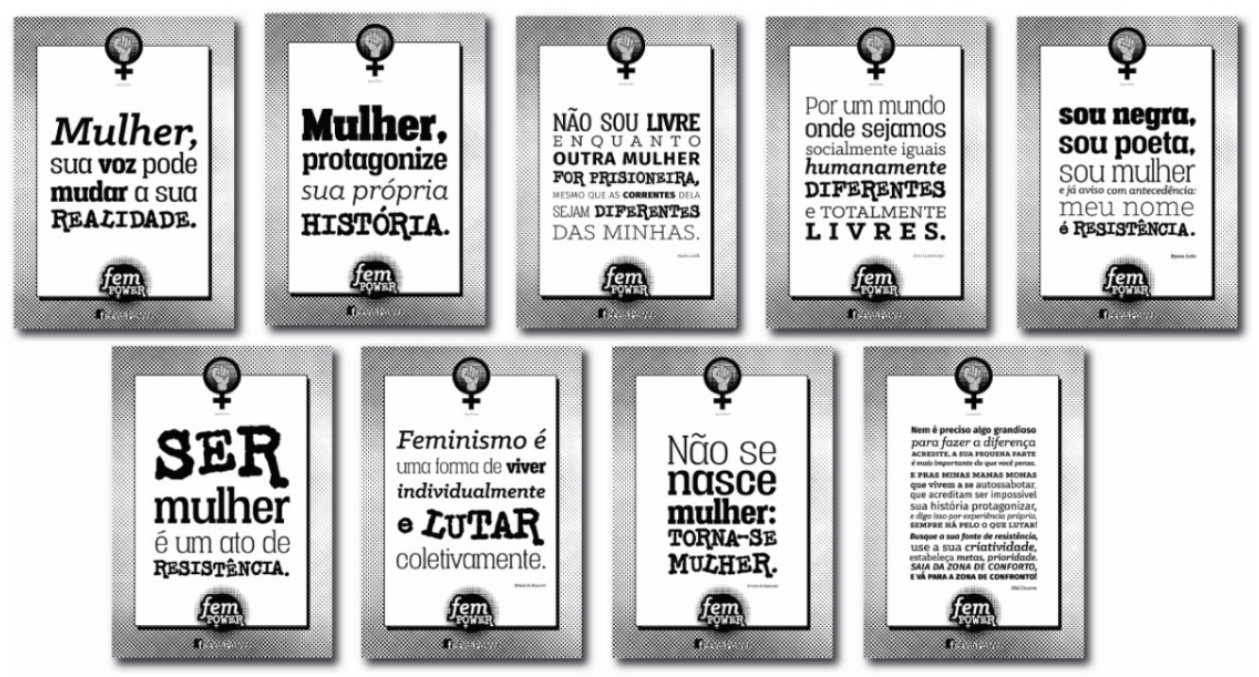

Fonte: Elaborado pelos autores (2017).

Com base na categorização de Moles (1969), as sete séries de cartazes deste projeto se caracterizam como cartazes desenhados, em preto e branco, argumentadores, de estilo moderno e simbólicos.

\subsection{Elaboração}

Nesta fase, foram feitos mockups digitais (Figura 10) com a ferramenta Photoshop para a aplicação de cartazes no ambiente urbano. Também foram criadas páginas virtuais em mídias sociais (Figura 11) para divulgar o Projeto FemPower.

Figura 10 - Simulação de colagem dos cartazes.
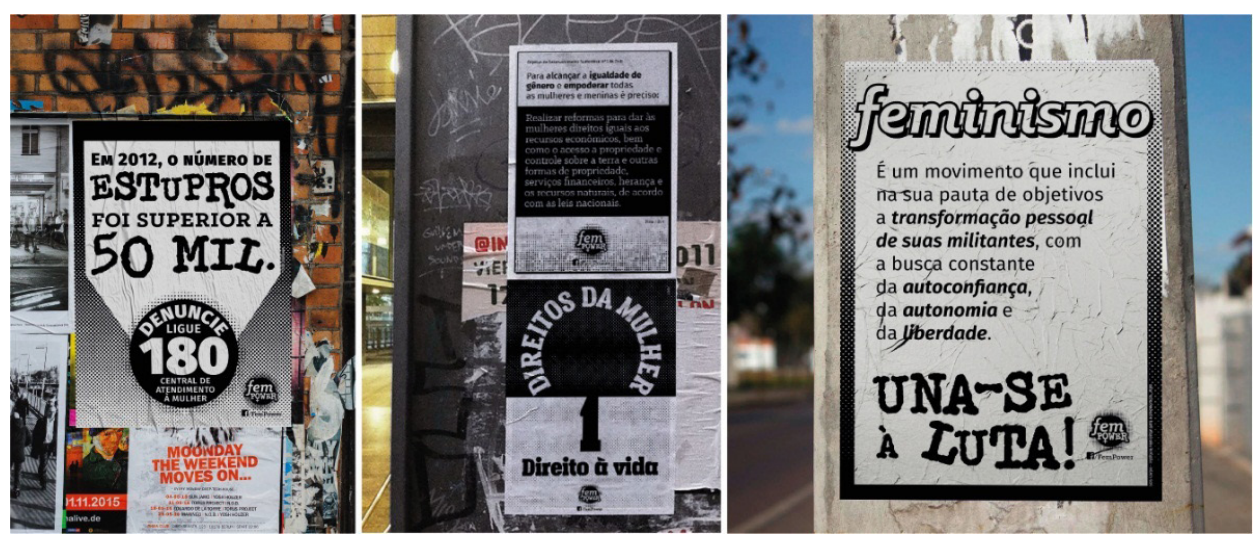

Fonte: Elaborado pelos autores (2017). 
Figura 11 - Simulação do Projeto nas Mídias Sociais..
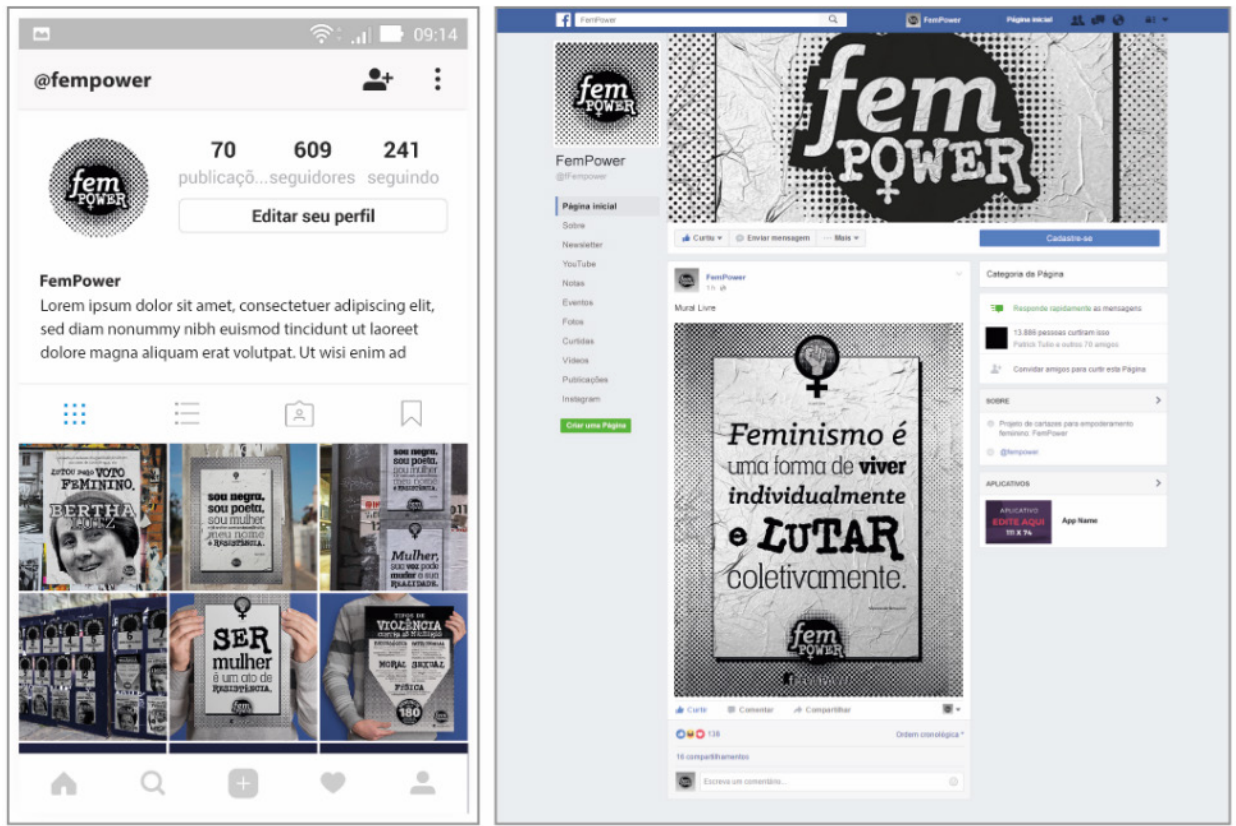

Fonte: Elaborado pelos autores (2017).

\subsection{Verificação}

Para esta fase foi criado um segundo formulário na ferramenta Typeforms.com, denominado Questionário Virtual de Verificação de Alternativas, enviado aos participantes da pesquisa de campo para avaliar as soluções desenvolvidas e basear novos ajustes, além de validar o seu objetivo de mostrar o Design Gráfico Social e verificar a utilização do cartaz como instrumento para o empoderamento feminino. O Questionário de Verificação apresentou as duas coleções de cartazes criados, cada uma delas acompanhada de quatro blocos de perguntas sobre linguagem, compreensibilidade, sobre o tema do empoderamento, e ainda sobre compartilhamento dos cartazes. Antes de avaliar, os participantes observaram visualmente as coleções, com exemplos de aplicação urbana, e acessaram as imagens com alta qualidade, através de redirecionamento para a página do projeto na rede social Facebook. As perguntas eram de preenchimento obrigatório. O Questionário recebeu 89 visitas e obteve um total de $24 \%$ de participações, ou seja, 21 respostas, em um período de 15 dias (15/06 a 24/06/2017), levando em média 11m05seg para o seu preenchimento e envio.

\section{CONSIDERAC̣ÕES FINAIS}

Ao atentar para a invisibilidade das mulheres, dentre outros aspectos dessa realidade ainda presente na sociedade, constata-se que a Comunicação Visual oferece uma das ferramentas sociais mais importantes para colaborar na diminuição dessa condição, podendo ser apenas o início de um longo caminho em busca da equidade social entre mulheres e homens. O Cartaz, ao 
servir como instrumento voltado ao coletivo ajuda a promover a Igualdade de Gênero e favorece o empoderamento feminino. O designer social tem, desta forma, muito a contribuir em favor da mudança de comportamento dessa sociedade. Acredita-se que tal objetivo foi atingido de forma satisfatória, visto que o produto final foi avaliado pelos participantes através de um segundo questionário virtual, destinado à apreciação da solução desenvolvida, no qual as respostas vão basear novos ajustes do produto, além de terem validado o objetivo da pesquisa. A avaliação teve um resultado positivo, desta forma, este trabalho finaliza-se cumprindo o seu propósito de colaborar na promoção da igualdade de gênero e mostrar o cartaz como instrumento social de empoderamento feminino, de caráter popular e democrático, tornando-se um motivador à continuidade e avanço de pesquisas na área, contribuindo para futuros projetos sociais relacionados a este tema. Não pode ser encarado como um trabalho conclusivo, mas como uma base de organização de informações sobre o desenho gráfico de cartazes como instrumento social, preparada com o propósito de subsidiar novas reflexões, além de ser uma proposição para trabalhos futuros. 


\section{REFERÊNCIAS}

ARCHER, Bruce L. Systematic methods for designers. London: The Council of Industrial Design, 1966.

BAQUERO, Rute Vivian Ângelo. Empoderamento: instrumento de emancipação social? Uma discussão conceitual. Revista Debates, Porto Alegre, v. 6, n. 1, p. 173-187, jan./abr. 2012.

BROD JÚNIOR, Marcos. Desenho de embalagem: o projeto mediado por parâmetros ecológicos. 2004. 210 f. Dissertação (Mestrado em Engenharia de Produção) - Universidade Federal de Santa Maria, Santa Maria, 2004.

BROD JÚNIOR, Marcos. Desenho industrial: apresentar, lembrar e reforçar princípios. In: GUIMARÃES, Lia Buarque de Macedo (Org.). Design/ desenvolvimento de produto: conceitos, definições e modelos. Porto Alegre: FEENG/UFRGS, 2009. v. 1. p.

FRASCARA, Jorge. Diseño gráfico para la gente: comunicaciones de masa y cambio social. Buenos Aires: Infinito, 2004.

FRASCARA, Jorge. El diseño de comunicación. Buenos Aires: Infinito, 2006.

GIL, Antonio Carlos. Métodos e técnicas de pesquisa social. 4. ed. São Paulo: Atlas, 1994.

GOMES, Luiz Antônio Vidal de Negreiros. Criatividade \& design: um livro de desenho industrial para projeto de produto. Porto Alegre: Ed. sCHDs, 2011.

GONZALES, Roseli Fragoso. A importância do cartaz de rua nos dias de hoje. Revista Belas Artes, São Paulo, v. 5, n. 13, set./dez. 2013.

HOLLIS, Richard. Design gráfico: uma história concisa. São Paulo: M. Fontes, 2000.

KIRKHAM, Pat (Ed.). Women designers in the USA, 1900-2000: diversity and difference. London: Yale University Press, 2001.

LIDWELL, William; HOLDEN, Kristina; BUTLER, Jill. Princípios universais do design. Porto Alegre: Bookman, 2010. 
LÖBACH, Bernd. Design industrial: bases para a configuração dos produtos industriais. Tradução de Freddy Van Camp. Rio de Janeiro: E. Blücher, 2000.

MAGESTE, Gizelle de Souza; MELO, Marlene Catarina de Oliveira Lopes; CKAGNAZAROFF, Ivan Beck. Empoderamento de mulheres: uma proposta de análise para as organizações. In: ENCONTRO DE ESTUDOS ORGANIZACIONAIS DA ANPAD, 5., 2008, Belo Horizonte. Anais... Rio de Janeiro: ANPAD, 2008.

MEDEIROS, Ligia Maria Sampaio de; GOMES, Luiz Antonio Vidal de Negreiro. O papel do desenho industrial no planejamento de produto. Formas \& Linguagens, ljuí, n. 5, p. 81-99, jan./jun. 2003.

MOLES, Abraham Antoine. O cartaz. Tradução de Miriam Garcia Mendes. São Paulo: Perspectiva, 1969.

MONTEIRO, Gizela Gomes. Empowerment: uma estratégia de luta contra a pobreza e a exclusão social em Cabo Verde. O caso de Lajedos. 2008. 172 f. Dissertação (Mestrado em Desenvolvimento, Diversidades Locais e Desafios Mundiais) - Instituto Superior de Ciências do Trabalho e da Empresa, Lisboa, 2008

NEVES, Flávia de Barros. Design gráfico e mobilização social: cartazes contra a guerra do Iraque. 2009. Dissertação (Mestrado em Desenho Industrial) Universidade do Estado do Rio de Janeiro, Rio de Janeiro, 2009.

ONU. ORGANIZAÇÃO DAS NAÇÕES UNIDAS. Dados e conteúdo. Disponível em: <http://www.onu.org.br>. Acesso em: 21 maio 2016.

ONU MULHERES. Dados e conteúdo. 2010. Disponível em: <http://www. onumulheres.org.br>. Acesso em: 21 maio 2016.

REDIG, Joaquim. O sentido do design. Brasil: Imprinta, 1983.

REDIG, Joaquim. Sobre desenho industrial (ou design) e desenho industrial no Brasil. Porto Alegre: Fac-simile; UniRitter, 2005.

RODRIGUES, Irene G. O olhar antropológico do designer. In: MOURA, Mônica (Org.). Faces do design 2: ensaios sobre arte, cultura visual, design gráfico e novas mídias. São Paulo: Rosari, 2009. p. 81-87.

SILVA, Carmen; CAMURÇA, Silvia. Feminismo e movimento de mulheres. Recife: SOS Corpo; Instituto Feminista para a Democracia, 2010. (Mulheres em Movimento, 1). 
SILVA, Hertha Tatiely. Desvios: cartaz lambe-lambe, comunicação visual e arte nos espaços de trânsito. 2015. 96 f. Dissertação (Pós-Graduação em Comunicação) - Universidade Federal de Goiás, Goiânia, 2015.

SPERB, Daniel Quintana et al. Sistema de letramento e ensino de fatores projetuais. Estudos em Design, Rio de Janeiro, v. 22, n. 1, 2014.

VILLAS-BOAS, André. O que é [e o que nunca foi] design gráfico. Rio de Janeiro: Ed. 2AB, 2003.

WIKIPEDIA. Girl Power. Disponível em: <https://pt.wikipedia.org/wiki/ Girlpower>. Acesso em: 20 maio 2016. 